\title{
Study of the Compressive Strength of Mortars as a Function of Material Composition, Workability, and Specimen Geometry
}

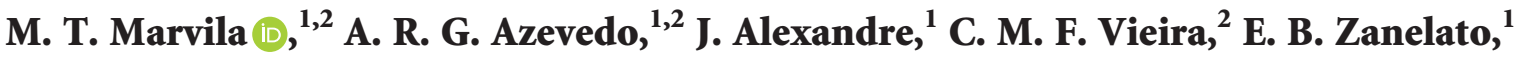 \\ G. C. G. Delaqua, ${ }^{2}$ G. C. Xavier, ${ }^{1}$ and S. N. Monteiro ${ }^{3}$ \\ ${ }^{1}$ Civil Engineering Laboratory, LECIV, State University of the Northern Rio de Janeiro, UENF, Av. Alberto Lamego, 2000, \\ Campos dos Goytacazes, RJ 28013-6022, Brazil \\ ${ }^{2}$ Advanced Materials Laboratory, LAMAV, State University of the Northern Rio de Janeiro, UENF, Av. Alberto Lamego, 2000, \\ Campos dos Goytacazes, RJ 28013-6022, Brazil \\ ${ }^{3} I M E-M i l i t a r y$ Institute of Engineering, Department of Materials Science, Praça General Tibúrcio, 80, Praia Vermelha, Urca, \\ Rio de Janeiro, RJ 22290-270, Brazil
}

Correspondence should be addressed to M. T. Marvila; markssuel@hotmail.com

Received 16 August 2019; Accepted 13 January 2020; Published 11 February 2020

Academic Editor: Aiguo Song

Copyright (C) 2020 M. T. Marvila et al. This is an open access article distributed under the Creative Commons Attribution License, which permits unrestricted use, distribution, and reproduction in any medium, provided the original work is properly cited.

In the present work, the statistical dispersion of the mortar compressive strength as a function of the geometric parameters of the specimens as well as the effect of the mortar workability difference on the compressive strength was investigated. For this purpose, specimens were prepared for six types of mortars: two conventional mortars in the proportions of $1: 1: 6$ and $1: 2: 9$ of cement, hydrated lime, and sand, respectively, two with clay replacing lime, and two with marble waste in place of lime. The results confirm the difference between the results found for the two geometries due to the differences in the heights of the molding layers and show that the workability of the mortar modifies the resistance properties, especially in the cylindrical mold where the molding of the specimens is more complex. By comparing the differences between the destructive test results and those defined by the Finite Element Modeling (FEM) for conventional mortars, it was clear that the effect of excess material in the sample during the compression tests did not change the strength properties studied. This facilitates the performance of the assay as specimens may be used excessively on the side without the need for sample rectification.

\section{Introduction}

The Brazilian construction industry occupies a prominent place in the country economy. According to the Civil Construction Industry Union it participates in $6 \%$ of the Gross Domestic Product [1]. Cementitious materials, such as concrete and mortar, are used in large scale by the civil construction, mostly due to their compressive strength [2]. In fact, concrete and mortar are composite materials and depending on the fraction of a phase incorporated they will present specific properties for each mixture. In order to determine the compressive behavior of these materials, mathematical modeling and destructive tests with proper specimens are performed and compared.
Usually, the compression tests are conducted with cylindrical specimens for concrete and prismatic for mortar, as per the Brazilian standards [3]. However, some international standards use specimens with different geometries, including cylindrical, to evaluate the compressive strength in mortars $[4,5]$. For mortars, another important parameter is the workability, i.e., the measure that evaluates the ease at which the material is molded [6]. One objective of this work is to determine the effect of mortars workability on their compressive strength.

Mathematical modeling is also extensively applied in civil engineering to interpret the mechanical behavior of construction materials. Among the modeling methods, stands the well-known Finite Element Method (FEM). This method consists of numerical approximative-based solutions for 
differential equations that are very useful for structural engineering $[7,8]$. The great advantage of the FEM is to use local approximations in subdomains, generated from the original domain, instead of using mathematical solutions in a global character. To obtain more accurate result, one may increase the number of subdomains. A relevant point regarding the application of the FEM is the possibility of evaluation the mechanical behavior of the periferical region (outer modes) around the investigated domain. A brief explanation of this procedure is now presented.

Figure 1 [9] shows two neighboring elements named as $\Omega(1)$ and $\Omega(2)$. Also in Figure $1, X(1)$ and $X(2)$ represent two outer nodes for each element. Constraints are included to the problem represented by $\Gamma \sigma, \Gamma u$, and $\Gamma c$ that correspond to loading conditions of displacement (supports) and boundary conditions (in the contact between two elements), respectively [9]. These conditions are included in the original domain and passed to defined finite elements. After the definition of the finite element grid and the type of element to be used in the modeling (linear, triangular, and quadratic), the characteristic matrices corresponding to each element can be developed and then grouped, composing the global system of equations [9].

The solution of this system gives the values of the unknowns in the nodal points. As for the nodes that border different elements, the value of the problem variables must be the same, regardless of the boundary conditions considered. In this way, it is also possible to obtain the values of the unknowns in the other points of an element using the calculated values of the nodal points, which function as interpolation functions [10].

Thus, through the imposition of boundary conditions, which represent the applied loads to the original domain and the predefined parameters, it is possible to obtain the deformation and strength responses in the whole domain of the problem defined at the beginning of the modeling [10].

Several works have studied the correlation of experimental parameters obtained through experimentation data, with parameters obtained by means of mathematical modeling [11-14].

Thus, the main objective of this work was to compare results of mortar numerical modeling, using outer nodebased FEM, and experimental data obtained in comparison tests of mortar specimens with distinct geometries (cylindrical and prismatic) and different workabilities.

\section{Materials and Methods}

To evaluate the influence of workability and specimen geometry on mortar compressive strength, six different mixtures were chosen. Two conventional mortars containing proportions of $1: 1: 6$ (REF116) and $1: 2: 9$ (REF129) of Portland cement, hydrated lime and natural sand, two mortars with clay replacing hydrated lime (CLA116 and CLA129), and two containing marble waste replacing hydrated lime (MAR116 and MAR129). The amount of water used was defined using the consistency limit of $260 \pm 5 \mathrm{~mm}$, which is associated with mortar workability, as recommended by the Brazilian ABNT NBR 13276 standard [15]. A

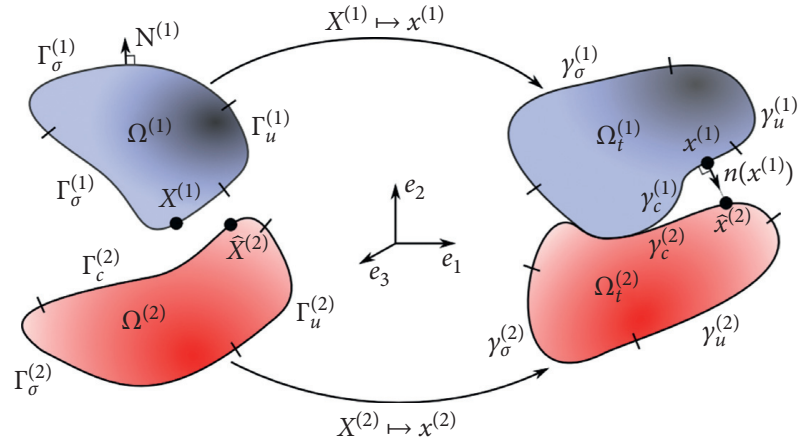

FIGURE 1: Schematic for two FEM subdomains in contact with outer nodes [9].

consistency test was performed on mortars REF116 and REF129 to define the amount of water required to maintain the workability index at $260 \pm 5 \mathrm{~mm}$. After that, the same amount of water was used to perform the tests on mortars CLA116, CLA129, MAR116, and MAR129.

Both prismatic and cylindrical specimens were fabricated by adding each mortar mixture with water inside corresponding metallic molds. After drying the specimens were removed from the mold and left still for 28 days.

For each of mortar mixture studied, 6 specimens were prepared with the dimensions $40 \times 40 \times 160 \mathrm{~mm}$ for prismatic and 100 (length) $\times 50$ (diameter) $\mathrm{mm}$ for cylindrical geometries. The specimens were subjected to compression tests, according to the Brazilian ABNT NBR 13279 standard [3]. It is noteworthy that the surfaces of the cylindrical specimens were regularized by capping and neoprene was used during the test to soften possible imperfections in the specimens.

Figure 2 illustrates the compression test for specimens with different geometries. Tests were conducted in an EMIC machine, with a $30 \mathrm{kN}$ load cell, at room temperature $\left(\sim 25^{\circ} \mathrm{C}\right)$ and loading speed of $500 \pm 10 \mathrm{~N} / \mathrm{s}$ as per the Brazilian ABNT NBR 5739 [16]. A regularization of the surface of the specimens that are in contact with the press was performed, allowing the mechanical strength test to be adequate.

The excess material, which eventually exists on the sides of the prismatic specimen (Figure 2(a)) during the compression test had its effect evaluated using two FEM models, 1 and 2, with different boundary conditions, as schematically shown in Figure 3. The first one (Figure 3(a)) restricts the mortar at the base of the test, applying loads on the top of the material. The second model (Figure 3(b)) includes lateral restrictions, simulating that the excess of mortar on the side of the material creates a restriction of movement in these directions. The analysis of the effect of excess material on the specimens is important, since the Brazilian standard recommends that the specimens be rectified before the test execution. With the proposed modeling, it is expected to prove that grinding is not necessary, since the excess material has no effect on the specimens.

For the modeling, the software ABAQUS/CAE was used, considering a material with cubic geometry of $40 \times 40 \times 40 \mathrm{~mm}$, originated after the flexural rupture of the 


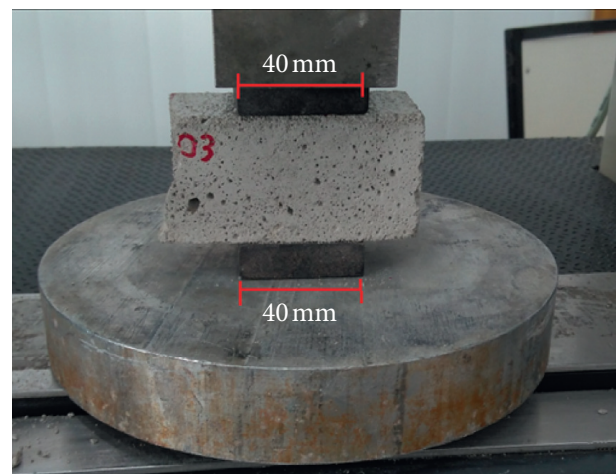

(a)

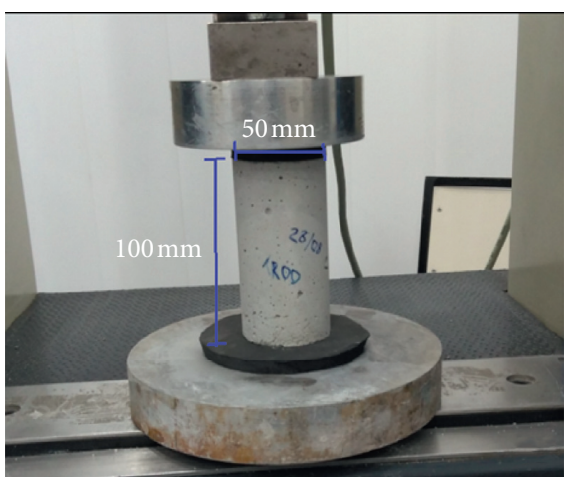

(b)

Figure 2: Illustration of compression test for both (a) prismatic and (b) cylindrical specimens.

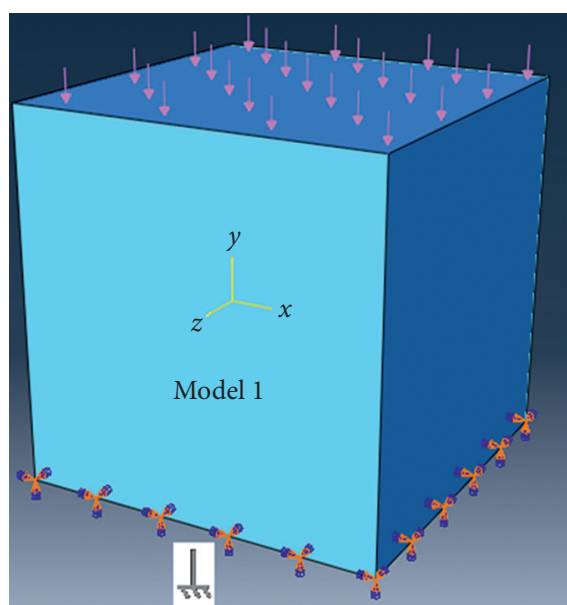

(a)

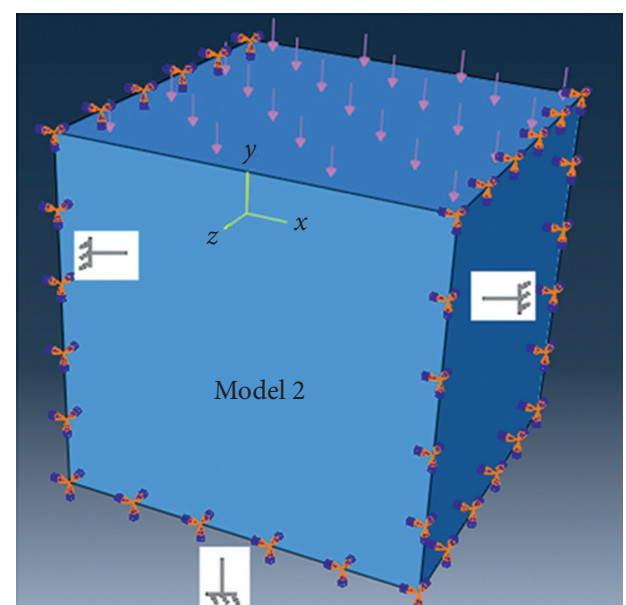

(b)

Figure 3: Loads and constraints used in model one (a) and two (b).

prismatic specimens of $40 \times 40 \times 160 \mathrm{~mm}$. The domain was divided into 1000 elements. The elastic parameters of the mortars were established based on the specialized literature. It was chosen to use 0.2 as Poisson's coefficient as well as the values of $1.80 \mathrm{GPa}$ and $4.00 \mathrm{GPa}$ for the elastic modulus of the mortars REF116 and REF12, respectively [17-19].

\section{Results and Discussion}

3.1. Analysis of Material Composition. The results obtained for the tests of compressive strength in cylindrical and prismatic specimens as well as the workability results from the, consistency tests, also known as the flow table, are presented in Figure 4.

While mortars containing clay (CLA) impair the workability, the ones containing marble (MAR) waste enhance this property when comparing to the reference (REF) mortars. The clay presents relatively thicker particles, while the marble waste thinner particles, as shown in Figure 5. This difference in particle size can justify the difference of workability. In addition, reference 1:1:6 mortars (REF116) show lower workability than $1: 2: 9$ mortars (REF129) due to

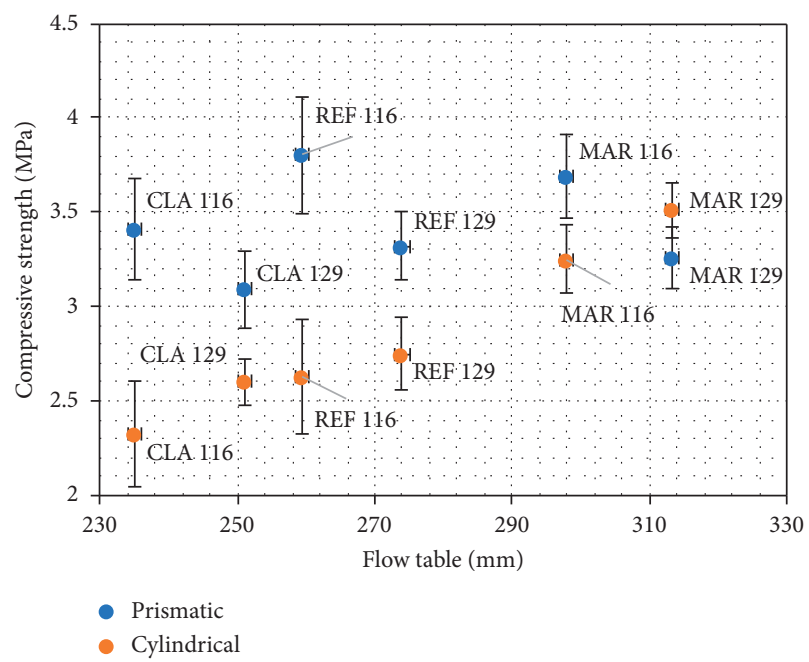

FIGURE 4: Results of compressive strength to prismatic and cylindrical geometries and of workability for the studied mortars.

the comparatively greater amount of cement and minor amount of hydrated lime. This behavior is usually found in mortars and has been reported [20-24]. 


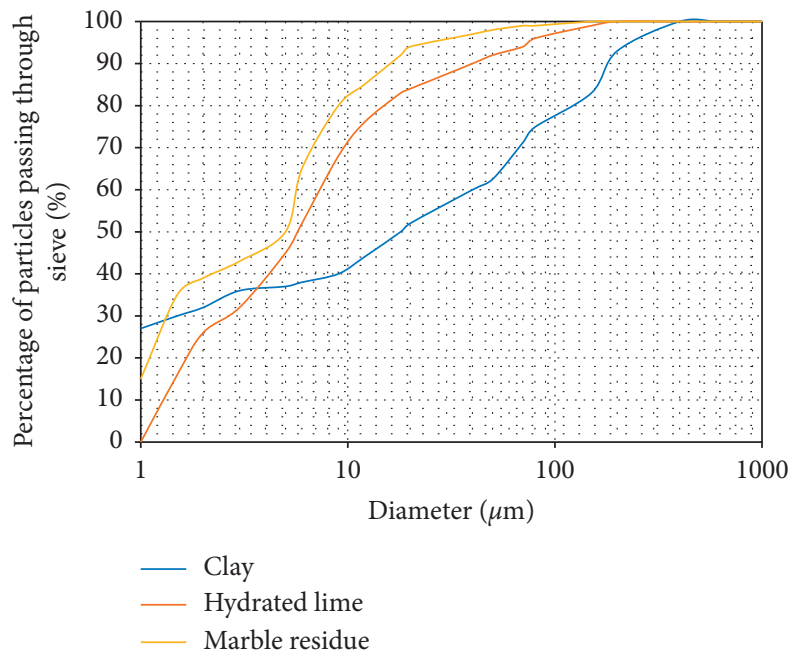

Figure 5: Granulometric curve of hydrated lime, clay, and marble waste.
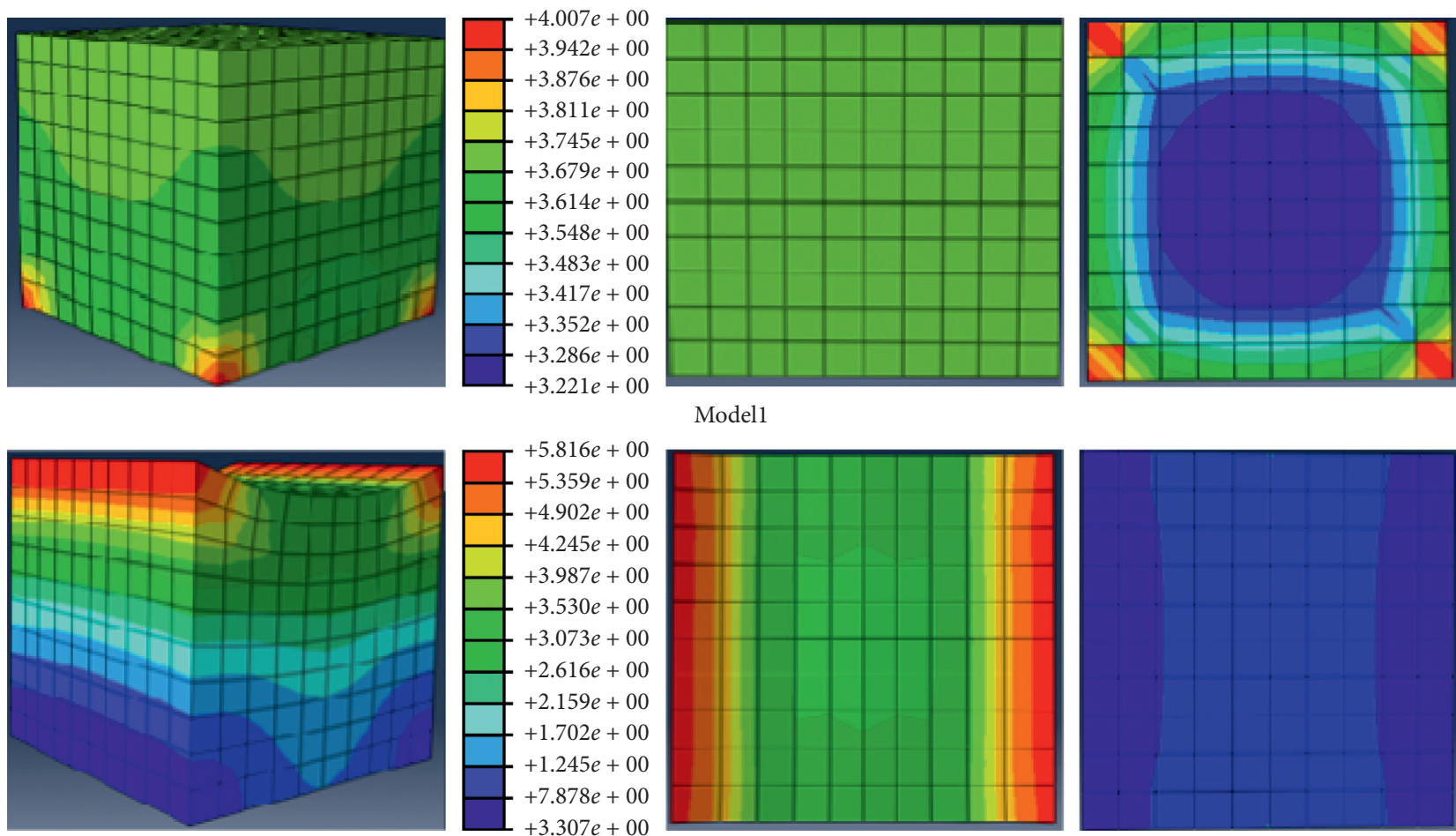

Model1
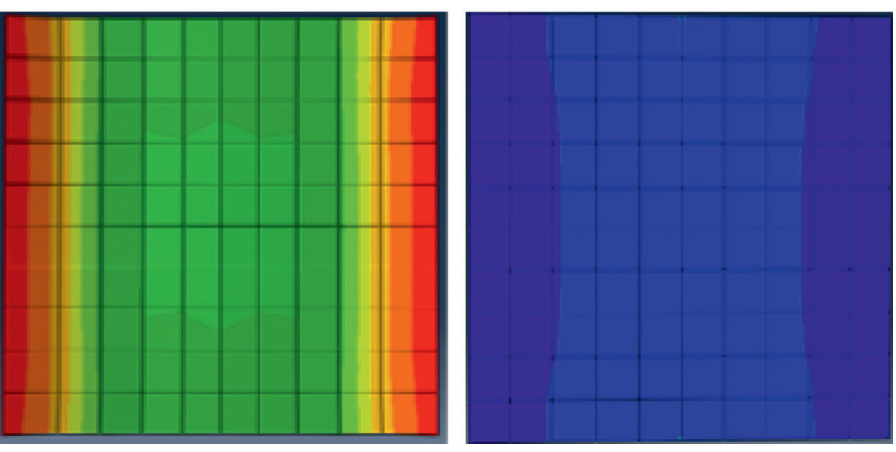

Model2

FIgURE 6: Results of the mathematical modeling for REF116 mortar.

Thus, it is found that the composition of mortars directly affects the workability parameters of the material, where mortars with finer particles (such as marble residue) show an increase in workability. The use of coarser particles in the material increases the friction between the particles that make up the material, which in the fresh state still do not behave homogeneously. This impairs the workability properties according to the results obtained for clay containing mortars.
3.2. Analysis of Specimen Geometry. When comparing the results shown in Figure 4, for cylindrical specimens, there is no statistically significant difference between $1: 1: 6$ and $1: 2: 9$ mortars. For mortar with marble (MAR) waste the difference in compressive strength is relatively lower than that for $1: 2: 9$ mortars (CLA129) containing lime and clay. It is also lower than $1: 1: 6$ (CLA116) for the same mixture. This behavior can be justified by the preparation of the samples that occur in two layers, receiving 30 strikes on the table on each layer. 

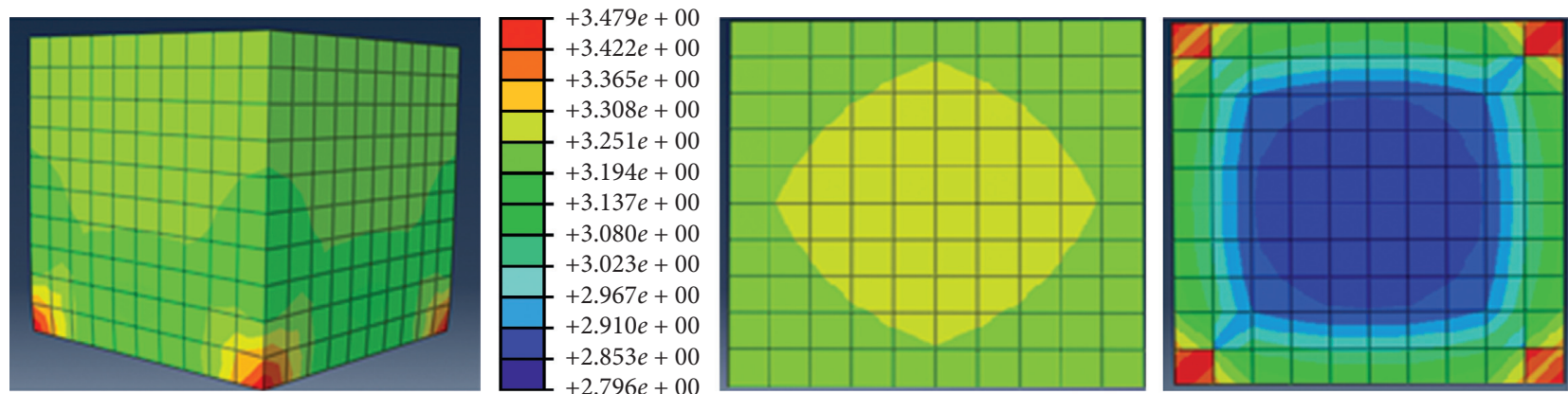

Model 1
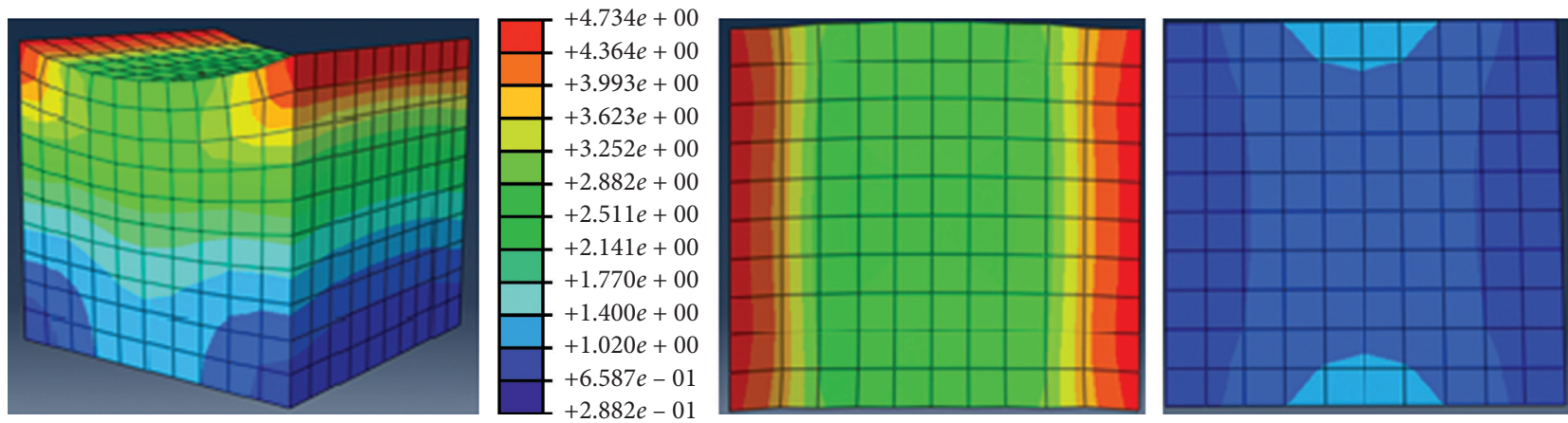

Model 2

Figure 7: Results of the mathematical modeling for REF129 mortar.

The height of the prismatic samples is $40 \mathrm{~cm}$ while that for the cylindrical sample is $100 \mathrm{~cm}$, meaning that each layer has 20 and $50 \mathrm{~cm}$ for prismatic and cylindric samples, respectively. The difference between the height of the prismatic and cylindrical layer on the samples is too small to affect the density of the material for a deposition in 2 layers considering the great workability of the marblebased mortars. However, the lower workability is enough to affect the other specimens with the same difference in height. Moreover, this behavior can justify the lower results of the cylindrical samples as compared with the prismatic ones $[25,26]$.

3.3. Analysis of Excess Material in the Sample. Figure 6 shows the FEM results presented by models 1 and 2 for REF116 mortar, while Figure 7 presents the results for REF129 mortar.

Comparing the critical region of model 1 of Figures 6 and 7 with the shape of rupture obtained in compression tests of prismatic specimens, it is found that there is an equivalence of behaviors. In principle it provides evidence that model 1 is the best for studying the proposed mortars. Additionally, the values of compressive strength obtained experimentally for REF116 and REF129 were, respectively, 3.81 MPa and 3.32 MPa. Using model 1, the resistance values obtained were $4.0 \mathrm{MPa}$ and $3.5 \mathrm{MPa}$. This leads to a relative error of $4.92 \%$ and $4.57 \%$, respectively, which can be considered as very low. However, by using model 2, the resistance values increase to $5.8 \mathrm{MPa}$ and $4.7 \mathrm{MPa}$ for mortars REF116 and REF129, respectively, leading to relatively larger errors of $34.49 \%$ and $29.87 \%$ [27].
Thus, model 1 presents a better mathematical adjustment to the experimental data obtained. This supports the hypothesis, raised previously, that the excess mortar on the sides of the specimens does not produce any restrictive effect on the equipment setup to maintain the dimensions of $40 \times 40 \mathrm{~mm}$.

Thus, the recommendations contained in the NBR 13279 standard are not necessary to be followed, since the rectification of the specimens before the mortar compression test does not change the results obtained in the test if the excess specimens are used. This is because the amount of material present on the side of the specimens is not sufficient to cause any crimping effect because it does not prevent the lateral displacements of the mortar. This information was confirmed by model 1 with more coherent values than those obtained in model 2 .

\section{Conclusions}

Experimental and modeling results confirm that the specimen geometry interferes with the properties of compressive strength since the results obtained for the prismatic were very different from those for the cylindrical specimens.

The workability of mortars directly interferes with the resistance on specimens with greater dimensions, although it does not significantly affect the resistance for mortars with low height. Furthermore, the higher the workability of a mortar, the lower its influence on the compressive strength.

The compressive strength results obtained for references REF116 and REF129 mortars, experimentally and by numerical modeling, revealed very close values when using model 1 that does not laterally limit mortars due to excess 
material during the test. This model presents relative errors of $4.92 \%$ and $4.57 \%$ for REF116 and REF 129 , respectively, and indicates the shape of rupture that occurs during the compressive strength test.

\section{Data Availability}

The data used to support the findings of this study are available from the corresponding author upon request.

\section{Conflicts of Interest}

The authors declare that they have no conflicts of interest.

\section{Acknowledgments}

The authors would like to acknowledge CNPq and CAPES for the financial support received for this study.

\section{References}

[1] SINDUSCON-DF, "Construção civil representa 6, 2\% do PIB Brasil," 2017, https://translate.google.com.br/?hl=pt-

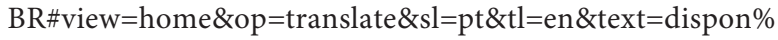
C3\%ADvel\%20em.

[2] R. A. Silva, P. de Castro Guetti, M. S. da Luz, F. Rouxinol, and R. V. Gelamo, "Enhanced properties of cement mortars with multilayer graphene nanoparticles," Construction and Building Materials, vol. 149, pp. 378-385, 2017.

[3] Associação Brasileira de Normas Técnicas-ABNT. NBR 13279, Mortar for Laying and Coating of Walls and Ceilings-Determination of Tensile Strength in Bending and Compression, Associação Brasileira de Normas Técnicas, Rio de Janeiro, Brazil, 2005.

[4] ASTM C 109, Standard Test Method for Compressive Strength of Hydraulic Cement Mortars (Using 2-in. or [50 mm] Cube Specimens), ASTM, West Conshohocken, PA, USA, 2016.

[5] TS EN 196-1, Standard Methods of Testing Cement-Part 1: Determination of Strength, European Committee for Standardization, Brussels, Belgium, 2016.

[6] N. Saikia and J. de Brito, "Use of plastic waste as aggregate in cement mortar and concrete preparation: a review," Construction and Building Materials, vol. 34, pp. 385-401, 2012.

[7] A. Seitz, A. Popp, and W. A. Wall, "A semi-smooth Newton method for orthotropic plasticity and frictional contact at finite strains," Computer Methods in Applied Mechanics and Engineering, vol. 285, pp. 228-254, 2015.

[8] A. P. C. Dias, A. L. Serpa, and M. L. Bittencourt, "High-order mortar-based element applied to nonlinear analysis of structural contact mechanics," Computer Methods in Applied Mechanics and Engineering, vol. 294, pp. 19-55, 2015.

[9] A. Seitz, P. Farah, J. Kremheller, B. I. Wohlmuth, W. A. Wall, and A. Popp, "Isogeometric dual mortar methods for computational contact mechanics," Computer Methods in Applied Mechanics and Engineering, vol. 301, pp. 259-280, 2016.

[10] S. Sitzmann, K. Willner, and B. I. Wohlmuth, "Variationally consistent quadratic finite element contact formulations for finite deformation contact problems on rough surfaces," $\mathrm{Fi}$ nite Elements in Analysis and Design, vol. 109, pp. 37-53, 2016.

[11] L. Shen, Q. Ren, L. Zhang, Y. Han, and G. Cusatis, "Experimental and numerical study of effective thermal conductivity of cracked concrete," Construction and Building Materials, vol. 153, pp. 55-68, 2017.
[12] B. V. Belleghem, R. Montoya, J. Dewanckele et al., "Capillary water absorption in cracked and uncracked mortar-a comparison between experimental study and finite element analysis," Construction and Building Materials, vol. 110, pp. 154-162, 2016.

[13] V. Nezerka, J. Antos, J. Litos, P. Tesárek, and J. Zeman, “An integrated experimental-numerical study of the performance of lime-based mortars in masonry piers under eccentric loading," Construction and Building Materials, vol. 114, pp. 913-924, 2016.

[14] E. Nasiri and Y. Liu, "Development of a detailed 3D FE model for analysis of the in-plane behaviour of masonry infilled concrete frames," Engineering Structures, vol. 143, pp. 603-616, 2017.

[15] Associação Brasileira de Normas Técnicas-ABNT. NBR 13276, Mortar for Laying and Coating of Walls and Ceilings-Determination of Consistency Index, Associação Brasileira de Normas Técnicas, Rio de Janeiro, Brazil, 2016.

[16] Associação Brasileira de Normas Técnicas-ABNT. NBR 5739, Concrete-Compression Tests on Cylindrical Specimens, Associação Brasileira de Normas Técnicas, Rio de Janeiro, Brazil, 2007.

[17] V. G. Haach, R. Carrazedo, and L. M. F. Oliveira, "Resonant acoustic evaluation of mechanical properties of masonry mortars," Construction and Building Materials, vol. 152, pp. 494-505, 2017.

[18] E. V. M. Carrasco, M. D. C. Magalhaes, W. J. D. Santos, R. C. Alves, and J. N. R. Mantilla, "Characterization of mortars with iron ore tailings using destructive and nondestructive tests," Construction and Building Materials, vol. 131, pp. 31-38, 2017.

[19] N. G. Silva and V. C. Campiteli, "Correlation between modulus of elasticity dynamic and mechanical strengths of cement mortars and sand with lime addition," Ambiente Construído, vol. 8, no. 4, pp. 21-35, 2008.

[20] M. T. Marvila, J. Alexandre, A. R. G. de Azevedo, and E. B. Zanelato, "Evaluation of the use of marble waste in hydrated lime cement mortar based," Journal of Material Cycles and Waste Management, vol. 21, no. 5, pp. 1250-1261, 2019.

[21] E. B. Zanelato, J. Alexandre, A. R. G. de Azevedo, and M. T. Marvila, "Evaluation of roughcast on the adhesion mechanisms of mortars on ceramic substrates," Materials and Structures, vol. 52, no. 3, 2019.

[22] M. T. Marvila, J. Alexandre, A. R. G. Azevedo, E. B. Zanelato, G. C. Xavier, and S. N. Monteiro, "Study on the replacement of the hydrated lime by kaolinitic clay in mortars," Advances in Applied Ceramics, vol. 118, no. 7, pp. 373-380, 2019.

[23] A. R. G. de Azevedo, M. T. Marvila, L. da Silva Barroso et al., "Effect of granite residue incorporation on the behavior of mortars," Materials, vol. 12, no. 9, p. 1449, 2019.

[24] A. R. G. Azevedo, J. Alexandre, L. S. P. Pessanha, R. S. T. Manhães, J. Brito, and M. T. Marvila, "Characterizing the paper industry sludge for environmentally-safe disposal," Waste Management, vol. 95, pp. 43-52, 2019.

[25] M. T. Marvila, A. R. G. Azevedo, J. Alexandre et al., "Correlation between the properties of structural clay blocks obtained by destructive tests and ultrasonic pulse tests," Journal of Building Engineering, vol. 26, Article ID 100869, 2019.

[26] A. R. G. de Azevedo, J. Alexandre, E. B. Zanelato, and M. T. Marvila, "Influence of incorporation of glass waste on the rheological properties of adhesive mortar," Construction and Building Materials, vol. 148, pp. 359-368, 2017.

[27] R. O. G. Martins, R. d. C. S. S. A. Alvarenga, L. G. Pedroti, A. F. d. Oliveira, B. C. Mendes, and A. R. G. d. Azevedo, "Assessment of the durability of grout submitted to accelerated carbonation test," Construction and Building Materials, vol. 159, pp. 261-268, 2018. 